\title{
Why Women are Self-Employed? Empirical Evidence from Pakistan
}

\author{
Muhammad Zahir Faridi \\ Assistant Professor \\ Department Of Economics, Bahauddin Zakariya University, Multan, Pakistan \\ Tel: 92-30-0680-1779Ｅ-mail: zahirfaridi4u@yahoo.com \\ Imran Sharif Chaudhry \\ Associate Professor \\ Department of Economics, Bahauddin Zakariya University, Multan, Pakistan \\ Tel: 92-30-0630-2072Ｅ-mail: imranbzu@yahoo.com \\ Muhammad Shaukat Malik \\ Assistant Professor, Management \& HRM \\ Institute Of Management Sciences, Bahauddin Zakariya University Multan, Pakistan \\ Tel: 92-30-0630-2202 E-mail: shoukatmalik@bzu.edu.pk
}

\begin{abstract}
In developing economies like Pakistan, the rising trend of women's labor participation has become the core indicator of growth and development. In this respect, the MDGs (Millennium Development Goals) relates to efficiency and equity, especially elimination of gender disparities in education, improvement of maternal health, lessening mortality rate among children and women empowerment are desirable goals. But still the representation of women in wage as well as in the self-employment sector is very low. The present study investigates the factors which influence women's participation in self-employment. Primary source of data is used for empirical analysis. Logistic regression technique is employed to estimate the women self-employment model. The findings indicate that age and experience positively affects women's self-employment. Further, it is concluded that education, location and number of dependents significantly reduce the women's work participation as self-employed worker. It is suggested that the government provide technical and vocational education to the women, and also give old age benefits just to minimize the dependency burden.
\end{abstract}

Keywords: Women Self-employment, Experience, Logistic regression, Dependency burden, Higher Education, Per Capita Income.

\section{Introduction}

The population of Pakistan indicates a double faced phenomenon. On the one side, population of the country is considered as an asset and performs an integral role in the growth and development process of the country. On the other hand, the high growth rate of population is a great hindrance in way of economic prosperity and development of the country. For examining the role of human capital in economic development, it is imperative to study both the qualitative and quantitative aspects of the population. At the time of independence in 1947, the total population of Pakistan was 32.5 million. By the year 2006-07, the population reached 156.77 million. The population of Pakistan has grown at an average rate of 2.6 percent per year. The changes in the labor force and employment level are affected by the population growth rate and its composition. This high growth rate of population shows that Pakistan will become the eighth most populous country in the world by the year 2010 (Govt. of Pakistan Economic Survey 2006-07).

Employment generation, poverty reduction and human resource development are the main features of Pakistan development policy. The employment led growth rate captures a central place in attaining the sustained development. Table 1 highlights the labor force participation (LFPR) among the region and gender based on crude activity rates in the years 1996-97 to 2005-06.

The labor force of Pakistan was estimated at 50.05 million on the basis of participation rate of 32.2 percent during the year 2005-06. During the two years, this rate has increased from 45.23 million to the present level by adding 4.82 million, both men and women. The present situation nevertheless is the information about a high dependency ratio. From the table 1, it is clear that the LFPRs though low, is increasing gradually over the years. The rural urban participation rates show also a gradual increase both for men and women for the last ten years. An increase of 3 percent female labor force participation in the urban areas is dominated by males i.e. ( 4.4 percent for males versus 2.0 percent for females). On the other hand, almost an increase of 4 percent in the rural areas is dominated by females i.e. 5.5 percent of females vs. 2.7 percent of males. Such satisfactory rise in labor force participation in rural areas, particularly for females and of males in urban areas represents the positive step for development of Pakistan's economy. This all has happened due to expansion of educational facilities and health facilities in rural areas for females and further providing employment opportunities in social as well as in economic sectors, both in rural and urban areas. 
Although, facts indicate a rising trend in female labor force participation over the period but still it is low as compared with other developing and developed nation. The issue of female's employment and labor market participation has given top priority in the developing nations generally and especially in Pakistan. The present analysis is arranged as follows. The first section provides a brief introduction and importance of study. Section 2 reviews the relevant literature, section 3 , discusses the data source and presents the methodology. Section four provides the results and discusses the findings. The final section concludes the whole discussion.

\section{Review of the literature}

There is an immense literature available on the issue of women participation in economic activities at the national and international level. Women represent a sizeable portion of the population and require a lot of attention. They are considered as a supporting factor in the economic development of the country and put a significant effect on overall business and economic activities. Hill (1983) concluded that husbands' wages were inversely related to women participating in the formal labor market but directly to women working for family business. Sheehan and Standing (1978) showed that age is less important by women participating in the labor market while education, social and environmental factors have significant impact on participation. Similar study made by Behrman and Wolfe (1984). They investigated that number of children had no larger effect on participation but schooling, experience and nutrition level had a significant impact on labor supply and wages.

Amin et al (1995) analyzed the different factors which directly or indirectly affect women's work participation. The results of the analysis showed that the income, purdah and patriarchal system had an inverse effect on female labor force participation and education, age and marital status had positive influence on female labor force participation. Irfan (1983) discussed the factors which determine the female labor supply. Using ordinary least square (OLS) and Logit estimation techniques, he found that higher level of education significantly influences the female LFPR, but only if they work as an employee. The study also shows that household per capita income is correlated with wage employment but self-employed women remained unaffected. Hafeez and Ahmad (2002) explored various factors which affect the decision of educated married women in participating in the labor market. Naqvi and Shahnaz (2002) made an attempt to explore the factors which influence women's decision regarding work participation and concluded that age and education were positively related to decision making and participation in economic activities but married women were less likely to participate.

Faridi et al. (2009) estimated the factors which influence the women's decision to join the labor market. They concluded that education significantly affects women's work participation. Rees and Shah, 1986; Georgellis and Wall, 2004; Do Trang, 2008; Blau David, 1985; Le Anht, 2000; and Blanchflower and Oswald, 1988 provided very informative studies on the issue of the self-employment. They concluded that education, health, experience family background, marital status turned out to be very significant factors.

Most of the studies reviewed focus on the factors which determine female labor force participation. But the aim of the present study is to identify different socio-economic factors which determine why women are self-employed. The importance of the study becomes more powerful and rational that women's participation as self-employed worker reduces public sector burden and expands the private sector, business sector by attracting more investment. Ultimately, this thing raises the process of economic development.

\section{Data Sources and Methodology}

\subsection{Data Sources}

In order to observe the factors which influence the women's decision to be self-employed, we have chosen district Bahawalpur as study area. Pakistan consists of 4 provinces and FATA (Federally administrated area). Punjab is the largest and densely populated province of Pakistan. It consists on 9 divisions and 34 districts. Bahawalpur district is one of them and is situated in the southern part of the Punjab. Bahawalpur is the largest district of Punjab, covering of an area of round about 24830 square $\mathrm{km}$. Total population of the district was 2.433 million or 243309 in 1998. Almost 72.7 percent of the total population is living in rural areas while the urban population is 665304 or 27.3 percent. Total females' participation in self - employment is 29 percent, out of which 38.2 percent are rural self employed and 18.6 percent are urban self - employed (Note 1). Primary source of data is used for analysis. Simple random sampling and stratified sampling techniques are employed to collect the data both from formal and informal sectors. A total of 164 women in the age cohort of 15-64 years are interviewed randomly both from urban and rural areas according to the population distribution. Our study includes human as well as non human capital related factors to see why women are self-employed.

The study is based on an empirical analysis. Women's decision regarding self-employment is analyzed at two stages. At the first stage, we present a preliminary analysis considering mean, standard deviation, skewness, and kurtosis of the selected variables and also pair wise correlation is constructed to examine the existence of multicollinearity. In the second stage of the analysis, the study report multivariate estimates of the self-employment model. The multivariate analysis of self-employment is structured in the framework of the conventional theory of utility maximization (Becker 1965), by using the maximum likelihood Logit model. 


\subsection{The self-employment model}

There are numerous macro and micro-economic variables that decide whether women who desire to participate in economic activities being salaried employed or own account or self-employed worker (Note 2). Decision regarding labor supply is influenced by some of these factors and others require decision. We start with general function.

$$
Y_{i}=f\left(X_{1}, X_{2}, \ldots \ldots, X_{n}\right)
$$

Where $Y_{i}$ indicates the women's decision in the labor market as self-employed worker. $Y_{i}$ is equal to " 1 ", if women participate in economic activities as self-employed worker and equal to zero if the women prefer to wage/ salary employment.

Following Blundell (1987) an index function, $\mathrm{WSE}_{\mathrm{i}}$ may be defined as that it depends on a vector of explanatory variables $Z_{\mathrm{i}}$. These factors make decision whether a woman should participate in self-employment activities or not. Hence the general model for self-employment is;

$$
\stackrel{*}{W S E_{i}}=\beta Z_{i}+\varepsilon_{i}
$$

Where WSE is a latent variable that apprehends the propensity of women "i" to be self-employed, $\mathrm{Z}_{\mathrm{i}}$ is a vector of remarked or noted factors held to affect the propensity of women "i" to be self-employed, $\beta$ is a vector of estimated coefficients and $\varepsilon_{i}$ is a random/disturbance error term.

$$
\stackrel{*}{W S} E_{i}=\beta Z_{i}+\varepsilon_{i}>0
$$

The woman would obtain self-employment where as if:

$$
\stackrel{*}{W S} E_{i}=\beta Z_{i}+\varepsilon_{i} \leq 0
$$

The woman would be wage/ salaried employed. The vector $Z$ pertains variables for age, experience, education, financial capital (Assets), marital status, number of dependents, number of children, husband salaried, location and family setup.

Where as, $W S E_{i}$ is a latent variable which is not directly observable, only dichotomous variable WSE is remarked which is defined as;

$$
\begin{array}{llll}
W S E & =1 & \text { if } & \stackrel{*}{W S E_{i}}>0 \\
W S E & =0 & & \text { Otherwise. }
\end{array}
$$

The probability of finding the women self-employment is;

$$
\begin{aligned}
& \operatorname{Pr} o b\left(W S E_{i}=1\right) \quad \operatorname{Pr} o b\left(\varepsilon_{i}>\beta Z_{i}\right) \\
& =1-\mathrm{F}\left(-\beta Z_{i}\right)
\end{aligned}
$$

Where $\mathrm{F}$ is the cumulative distribution function for $\varepsilon_{i}$. It is assumed that $\varepsilon_{i}$ is normally distributed with mean zero and constant variance [i.e. IN $\left.\left(0, \sigma^{2}\right)\right]$.

In our analysis, the explained variable is binary or indicator variable WSE. The inadequacy of linear probability model suggests that non-linear specification may be more appropriate. Therefore, a Logit or Probit econometric model is more useful and we use Logit model technique in our study. The Logit model hypothesizes the following cumulative probability density function.

$$
W S E=\frac{1}{1+e^{-\beta Z_{i}}}
$$

Where WSE is the probability that a women participates in economic analysis as self-employed, "e" is the exponential value. $\beta$ is the row vector of parameters and $Z_{i}$ is the column of the explanatory variables.

With the Logit model the natural $\log$ of the odds ratio of self-employment to wage/ salary employment, $\ln \left(\frac{W S E}{1-W S E}\right)$ is expressed as a linear function of explanatory variables, such as;

$$
\ln \left(\frac{W S E}{1-W S E}\right)=\beta Z_{i}
$$

Therefore, the estimated parameters are the Logit model register the effect on the log odds of a little change in the independent variables. Partial effects of independent variables on the probability of being self-employed are described by; 


$$
\frac{\partial W S E}{\partial Z k}=W S E(1-W S E) \hat{\beta} k
$$

Where $Z_{\mathrm{k}}$ is the $\mathrm{k}^{\text {th }}$ independent variable and $\beta k$ is its related estimated parameter. Conventionally, the marginal effects are evaluated at the sample mean self-employment rate (See Greene, 1993).

\subsection{Variables description}

The self-employment model which is specified above is general model, can be utilized as a guiding paradigm. Considering the theoretical rationale, the operational model depends upon the factors which are provided by the data. Generally, we have found in the past studies in the self-employment literature (e.g., Rees and Shah, 1986, Borjas, 1987, Evans, 1989, de Wit, 1993, Bernhardt, 1994, Kidd, 1993) that self-employment is determined by both human capital and non-human capital variables which are discussed below. The justification for including these variables in the women self-employment model and their expected relationships are interpreted below.

\subsubsection{Education}

Education is considered a vital factor in determining self-employment activities. In the literature of self-employment, it is observed that educational attainment is pleaded to apprehend a range of effects. On the one side, educational attainment may be pondered as a source of workers' managerial capability and hence workers are more likely to be self-employed. On the other side, it is expected that educated workers are more inclined to salary or wage employment as the attainment of higher level of education rises and higher level of education reduces the likelihood of self-employment. Therefore, we can not determine the effect of educational attainment in advance. So, it is not surprising that various studies have concluded mixed effects of educational attainment on self-employment. Kidd (1993) has concluded that tendency to be self-employed is not significantly influenced by the educational attainment. Further, according to Evans' (1989) study, it is found that self-employment is inversely and significantly influenced by the level of education among immigrants. In the present discussion, we have traced out the impact of education on self-employment in two ways. First, completed years of education are considered as continuous variable and secondly we have used various level of educational attainment as dummy variable in the self-employment model.

\subsubsection{Age/ Experience}

Age and experience are highly correlated. Experience and age move in same direction. The present study discusses the impact of both variables separately. There are two ways (approaches) to interpret the labor market experience. These are stock(Note 3) and flow (Note 4) approaches. According to stock approach, aggregation of work-related skills of an individual or worker is an indicator of labor market experience. It is assumed that there is positive relationship between experience and labor markets participation as self - employed worker. Experience and stock of managerial capability which is attained on the job trainings are directly related (Note 5) Hence it is expected that there is positive correlation between self-employment and labor market experience (Note 6). According to the flow approach, labor market experience that is related with the age of worker can be contemplated as the rate at which the aggregated stock of knowledge is attained. In this respect, as worker becomes aged, his learning ability reduces because it would be tougher for the worker to have complete command over the new technology. As a result, the knowledge increases at decreasing rate. So the expected sign of experience - squared $\left(\mathrm{EXP}^{2}\right)$ is negative and indicates non-linear relationship.

\subsubsection{Marital Status}

In the literature of economics, it is assumed that marriage represents stability. Thus it gives an appropriate background for risky self-employment. It is observed that married couples are interested to start their own business with joint finances just to maximize family profit. Therefore, a positive relationship is expected between marital status and self-employment.

\subsubsection{Household Assets}

Presence of household assets influences the self-employment positively. The study incorporates all types of assets (e.g. Land holdings, Live-Stocks, Shops, Rented Homes, Personal homes, Bank deposits, Gold, Foreign currency account etc) to find out their impacts on self-employment. It is expected that presence of household's assets and self-employment are positively related.

\subsubsection{Family Setup}

In the light of previous studies, it is observed that family setup has mixed effect on women work participation as self-employed worker. Here, the family setup means whether a joint family system or a nuclear family system. Nuclear family system is defined as such system which includes only husband and wife with or without children while joint family system considers other members of the family such as mother, father, brothers, sisters, grand father, grand mother, uncle and aunts. The major characteristics of the joint family system is that people living in combined family having common expenditure especially kitchen. 


\subsubsection{Per Capita Income}

Households' per Capita Income is an important economic indicator which measures the welfare and well-being of the family. Theoretically, it is expected that women are less likely to participate in the labor market being self-employed worker, as per capita income of the family is high or rising.

\subsubsection{Number of Dependents}

Theoretically, it is expected that number of dependents and women's self-employment is inversely related. The rationale behind this hypothesis may be that women's inside home activities may increase.

\subsubsection{Husband Salaried and Number of children}

From the review of the various studies regarding women's participation in the labor market, it is noted that women whose husbands are working and salaried employed and have more children are expected to be self-employed.

\subsubsection{Location}

Self-employment is also affected by the region of residence or location. The location is classified as rural and urban area. Therefore, it is expected that women belong to rural area are more likely to be involved in own business activities like working on farm, rearing live stock etc.

\subsection{Operational Model}

The operational model for estimating the women self-employment status is outlined in the following equation. In order to analyze the influence of different variables on self-employment, two specifications are chosen for estimation. The first specified model for women self-employment is given below:

$$
\begin{array}{r}
W S E=\alpha_{0}+\alpha_{1} A G E+\alpha_{2} E D C+\alpha_{3} P C I+\alpha_{4} P H A+\alpha_{5} M A R \\
+\alpha_{6} H S L+\alpha_{7} F S P+\alpha_{8} N D T+\alpha_{9} L C N+\alpha_{10} N C H+\mu_{i} \quad \ldots \ldots \ldots \ldots \ldots . . .(\mathrm{A})
\end{array}
$$

In the equation of women self-employment model, the independent variables are Age, Completed years of education, Per Capita income, Presence of household Assets, Marital Status, Husband Salaried, Family Setup, number of dependents, location and number of children.

In order to observe the influence of experience on women's self-employment, the study includes a continuous variable experience in the self-employment model. Experience is obtained by subtracting completed years of education and age of the women at the time of entry into the school from the completed age of the women. i.e. EXP $=\mathrm{AGE}-$ Education -5 . Further, we have introduced different levels of education as binary variables to analyze the contribution of education at each level in the women self-employment model. AGE and Completed years of education are omitted from the second equation just to remove the effect of multicollinearity.

$$
\begin{array}{r}
W S E=\beta_{0}+\beta_{1} E X P+\beta_{2} E X P^{2}+\beta_{3} P E D+\beta_{4} S E D+\beta_{5} H E D+\beta_{6} P C I+\beta_{7} P H A \\
+\beta_{8} M A R+\beta_{9} H S L+\beta_{10} F S P+\beta_{11} N D T+\beta_{12} L C N+\beta_{13} N C H+\omega_{i} \ldots \ldots \ldots .(\mathrm{B})
\end{array}
$$

The list of the variables for Logistic estimates of the determinants of women self-employment is given in the table 2 .

\section{Results and Discussions}

\subsection{Preliminary Analysis}

We have presented the preliminary analysis of data by providing the brief discussion on the profile of respondents and interpreting descriptive statistics of the some selected variables. Correlations among explanatory variables are also presented.

\subsubsection{Respondents' characteristics}

Overall 164 women are interviewed at random from formal as well as informal sectors. Out of which 106 or 64.63 percent women belongs to rural area and 58 or 35.37 percent women are living in urban area. Total percentage of women's participation in self - employment is 21.82 percent in the present study. Further, it is concluded that 15.79 percent self - employed women belong to urban locality while 25.0 percent self - employed women live in rural area.

\subsubsection{Descriptive Statistics}

Table 3 describes the basic statistics of some selected variables. The average age of self-employed women is 38.11 years with variability about mean is 13.26 . On the average, self-employed women's education in completed years is 10.62 years. The average per capita income of the family is 2387.70 rupees per month. The study indicates that the number of children is 3.18 on the average. In addition, the descriptive analysis reports that 0.49 or 49 percent women have education up to primary level (5 years of education) on the average and 0.17 or 17 percent respondents (women) have education up to secondary level (10 years of education). Similarly on the average, 0.34 or 34 percent respondents have higher degree in education (M.A/ M.Sc, professional, M.Phil, Ph.D).

\subsubsection{Correlation analysis}

We have presented the correlations matrix of different explanatory variables in the table 4 as preliminary investigations of the relationships. This correlation matrix is used to examine the multicollinearity among the 
variables. The explanatory variables, whose pair wise correlation is greater or equal to 0.83 , show the existence of multicollinearity. We have dropped those variables in the remaining analysis. From the table, it is obvious that age and experience are multicollinear. So we have used age and experience in separate equations to have perfect estimation.

\subsection{Multivariate Estimates}

Tables 5 and 6 present the Logit estimates of the determinants of women self-employment model. Each table consists of four columns. First column in each table describes the nature of the explanatory variables while others remaining three columns discuss the estimated parameters, their asymptotic Z-statistic and marginal effects respectively in each table. The marginal effects show the change in probability of being self-employment due to unit change in a given explanatory variable after holding all other variables as constant at their mean.

The present study uses two tailed test of significance or Z-statistic for determining the acceptance or rejection of null hypothesis to examine the reliability of the point estimates. For this purpose, we have used 1 percent, 5 percent or 10 percent level of significance. The intercept terms in the both equations of self-employment turns out to be negative and statistically highly significant. This significant result indicates that women's participation being self-employment may be influenced by omitted factors from the study. The values of McFadden $\mathrm{R}^{2}$ in both the equations are very low (i.e. 0.27 and 0.39 increases positively). Low level of $\mathrm{R}^{2}$ is a typical phenomenon in cross sectional studies. However, the quality of our estimates should not be gauged by this low $\mathrm{R}^{2}$. Overall performance of the self-employment model is judged by the highly significant LR-statistic.

Women's work participation being self-employed is influenced by age. We have found that probability of self-employment rises with age. The coefficient of age is positive and significant. In the second equation, we have used years of experience as a explanatory variable instead of age in years. The coefficient of experience (EXP) is positive and significant at 10 percent level of significance. The probability of women's work participation in the labor market as self-employed workers increases by 6 percentage points due to additional years of experience. The reason may be that self-employment or self-business requires more experience, courage, skill and management qualities. The negative coefficient of $\mathrm{EXP}^{2}$ indicates the non-linearity relationship.

Education plays a pivotal role in determining the self-employment activities. We have introduced both the completed years of education and different levels of education as explanatory variables in our self-employment model. In the first equation of self-employment model, we have observed that the coefficient of completed years of education (EDC) is positive and highly significant. The probability of women's self-employment increases by 1.2 percentage points as a result of an increase of one year of education. The reason may be that self-employment activities need managerial skill, efficiency, decision making ability and risk facing activities of the worker, which are acquired through more years of education.

In the second equation of self-employment model, the coefficients of PED and SED are positive and statistically significant at one percent level of significance. The reason may be that the low educated women are inclined to start up a business because low level of education is not sufficient in securing permanent salaried jobs. Our results are in line with the findings of verheul et. al (2006). In addition, we have noted in our study that the higher education (HED) has a strong negative and significant impact on women's decision to be self-employed. The probability of women's self-employment diminishes by about 34 percentage points due to an increase of one unit in higher education. The highly educated women's prefer to be salaried employed in Government and Semi-Government sectors because salaried employment is a secured, risk less and permanent source of income. Our study also supports verheul et. al (2006)'s findings.

Households' per Capita income is another important factor which influences women's participation in the labor market as an own account worker. The women are less likely to be self-employed by 1.2 percentage points because of an increase of one rupee in monthly per capita income. The presence of household assets has positive and significant impact on self-employment. The results of the study has pointed out that married women are less likely to be self-employed. The married women's probability of being self-employed workers drops by 2.9 and 3.5 percentage points in both equations respectively. But married status has insignificant impact. The reason may be that a large number of women have started their own business like embroidery, sewing, teaching the kids or tuition centre at home, and beauty parlor both in urban and rural areas. The coefficient of the husband salaried is positive and has significant impact on women's work participation. The interpretation may be that the women whose husbands are regular salaried workers are more inclined to start their own business especially at home like sewing clothes, embroidery or even rearing few animals etc, just optimal utilization of time simultaneously both in own business activities and at home activities like preparing meals.

We have observed that family setup (FSP) positively influences self-employment. Women belonging to joint family setup are more likely to be self-employed. The study revealed that the number of dependents has strong negative impact on women's work participation being self-employed. The probability of self-employment falls by about 5 percentage points in both equations due to an addition of one dependent in the family. The significant result indicates that women responsibilities at home increased because of high dependency burden. The coefficient of 
location (LCN) is negative and statistically significant. It means that rural women are more likely to be self-employed. The study has showed that the number of children raises the probability of self-employed.

\section{Conclusion and Policy Recommendations}

The role of women's participation in economic activities is considered a vital factor for growth and development. The women's labor market participation has become an important issue due to rising trend in women's population growth and labor force. The present study is conducted to examine the various socio-economic factors which determine why women are self-employed. The findings of the study reveal that the age and experience have positive and significant influence on women's work participation being self-employed. It is explored from the study that women's participation in self-employment activities is enhanced because of more years of education. When we consider various levels of education, the findings are very interesting. The low level of education motivates the women to start their own business but highly educated women are not inclined to be self employed. Presence of household assets, number of children and husband salaried positively and significantly influence the women's self-employment. In addition, the study concludes that Per Capita income, number of dependents and location reduce the women's work participation as self-employed worker. Our results are consistent with the previous studies as discussed in the literature.

The research has concluded that there is short of formal jobs for women in study area especially and generally in Pakistan. Lack of education at higher level and inconvenience in attaining higher education for women is main cause of women's self employment. The joint family system and larger size of family (more number of children) is another cause of women's inclination toward self - employed activities (in case of under developed countries in Pakistan). Further, study explores that high per capita income of the family reduces the women's participation in self - employment activities. But, low per capita is general phenomenon in poor countries generally and especially in Pakistan. Considering the study's conclusion, it is suggested that Government create formal jobs for women and also provide facilities in attaining higher education by establishing more educational institution especially health related and vocational training centers. There is a need to create awareness among the people to have a small size of family and independent family structure (nuclear family system).

\section{References}

A.M. Gill (1988). Choice of employment status and the wages of employees and the self-employed: some further evidence. Journal of applied econometrics, 3,229-234.

Amin, R., Robert, B. H. \& Yiping Li (1995). Poor women's participation in credit based self-employment: The impact on their empowerment, fertility, contraceptive use and fertility desire in rural Bangladesh. The Pakistan Development Review, 34(2).

Becker, G. S. (1965). Theory of the Allocation of Time, Economic Journal, 76, 493-517.

Behrman, J. A., \& Barbara I. W. (1984). Labor Force Participation and Earnings Determinants for Women in the Special Conditions of Developing Countries. Journal of Development Economics, 15, 259-288.

Blau, D. M. (1985). Self-employment and Self-Selection in Developing country Labour markets. Southern Economic Journal, 52(2), 351-363.

Blundell, R. (1987). Specification testing in Limited and Discrete dependent variable models. Journal of Econometrics, 34(2).

Borjas, G. (1987). The Self-employment of Immigrants. Journal of Human Resource, 21, 485-506.

D.G. Blanchflower \& A.J.Oswald (1998). What makes an entrepreneur?. Journal of labour Economics, 16, 26-60.

D.S. Evan \& B. Jovanovic (1989). An estimated model of entrepreneurial choice under liquidity constraints. Journal of Political Economy, 79, 808-827.

D.S. Evans \& L. S. Leighton (1989). Some empirical aspect of entrepreneurship. American Economic Review, 79, 519-535.

Do Thi, Q. T. (2008). Determinants of Self-employment: The Case in Vietnam. CES Working Paper No. 38.

Faridi, M. Z., Chaudhry, I. S. \& Mumtaz, A. (2009). The socio economic and demographic determinants of women work participation in Pakistan: Evidence from Bahawalpur District. A Research Journal of South Asian Studies, 24(2), 351-367.

G. de Wit (1993). Model of self-employment in a competitive market. Journal of Economic Surveys, 7, 367-397.

Georgellis, Y. \& Howard J. W. (2004). Gender Differences in Self-employment. Working Paper Series, Federal Reserve Bank of ST. Locus, MO 63102.

Glen, S. \& Guy, S. (1978). A note on economic activity of women in Nigeria. The Pakistan Development Review, 17(2).

Government of Pakistan (1999). District census report of Bahawalpur, Population Census Organization Statistics Division, Islamabad.

Govt. of Pakistan Economic Survey. (2006-07). Federal Bureau of Statistics, Ministry of Finance, Islamabad. 
Greene, W. H. (1993). Econometric Analysis. New York, MacMillan Publishing Company.

H. Rees \& A. Shah (1986). An empirical analysis of self-employment in the UK. Journal of Applied Econometrics, 1, 101-108.

Hafeez, A., \& Eatzaz A. (2002). Factors determining the labour force Participation decision of Education Married Women in Pakistan. Sustainable Development Policy Institute. (Working Paper Series No. 174.)

Hill, M. A. (1983). Female Labour Force participation in Developed and Developing Countries: Consideration of the Informal Sector. Review of Economics and Statistics, 65, 459-468.

I. Bernhardt (1994). Comparative advantage in self-employment and paid work. Canadian Journal of Economics, 27, 273-289.

Irfan, M., Z. Khan, S. Mubashir A., M. Rafiq \& Masood A. (1983). The Determinants of Female Labor force Participation in Pakistan, Islamabad. Pakistan Institute of Development Economic, Studies in Population, Labor Force and Migration Project Report No 5.

J.J. Heckman (1979). Sample selection bias as a specification error. Econometrica, 47, 153-161.

Le Anh T. (1999). Empirical studies of self-employment. Journal of Economic Surveys, 13(4), 381-417.

Le Anh T. (1999b). Self-employment and earnings among immigrant in Australia. International Immigration, 37, 383-412.

Le Anh T. (2000). The determinants of Immigrant Self-employment in Australia. International Migration Review, 34(1), 183-214.

M. P. Kidd (1993). Immigrant wage differential and the role of self-employment in Australia. Australia Economic Papers, 32, 92-115.

Naqvi Z. F. \& Lubna S. (2002). How do women decide to work in Pakistan?. The Pakistan Development Review, 41(4), Part II: 495-513.

Verheul I., Thurik R. and Grilo (2006). Determinants of Self - employment preference and realization of women and men in Europe and the United states. SCALES - Paper N. 200513.

Notes

Note 1. This information is taken from population census report of district Bahawalpur (1999).

Note 2. In the present study, self - employment is defined as the situation in which the workers (women) have started their own business both in rural and urban areas and also engaged in self made activities like working on farm and rearing livestock in rural areas and also engaged in embroidery, sewing clothes, teaching the kids at home or tuition centers and having beauty parlor or garments and cosmetics shops.

Note 3.See Evans' (1989)

Note 4.See Kidd (1993)

Note 5. See A. T. Le (2000)

Note 6.See Lucas (1978)

Table 1. Crude Labor Force Participation Rates * by Region and Gender (in percentage)

\begin{tabular}{|c|ccc|ccc|ccc|}
\hline Year & \multicolumn{3}{|c|}{ Total } & \multicolumn{3}{c|}{ Urban } & \multicolumn{3}{c|}{ Rural } \\
& Both & Male & Female & Both & Male & Female & Both & Male & Female \\
\hline $1996-97$ & 28.7 & 47.0 & 9.0 & 27.2 & 46.6 & 5.9 & 29.4 & 47.2 & 10.5 \\
$1997-98$ & 29.4 & 48.0 & 9.4 & 27.0 & 47.1 & 5.3 & 30.6 & 48.4 & 11.5 \\
$1999-00$ & 29.0 & 47.6 & 9.3 & 27.1 & 46.5 & 6.3 & 29.8 & 48.2 & 10.7 \\
$2001-02$ & 29.6 & 48.0 & 9.9 & 29.1 & 48.9 & 7.3 & 29.9 & 47.6 & 11.1 \\
$2003-04$ & 30.4 & 48.7 & 11.2 & 29.2 & 49.8 & 7.0 & 31.0 & 48.2 & 13.2 \\
$2005-06$ & 32.2 & 50.3 & 13.3 & 30.2 & 51.0 & 7.9 & 33.2 & 49.9 & 16.0 \\
\hline
\end{tabular}

Source: Labor Force Surveys (various issues).

*Labor force participation is estimated on the basis of crude activity rate (CAR) and refined activities rate (RAR) in Pakistan. The CAR is the percentage of labor force in total population where as refined labor force participation is the ratio of labor force 10 years and above to the total population. The labor force participation rates in table 1 are estimated on the basis of crude activity rate 
Table 2. List of the Variables used in the self-employment equations

\begin{tabular}{|c|c|}
\hline Variables & Description of variables \\
\hline \multicolumn{2}{|c|}{ Dependent variable } \\
\hline WSE & $\begin{array}{l}=1 \text { if woman is participating in economic activities as self-employment worker } \\
=0 \text { otherwise }\end{array}$ \\
\hline \multicolumn{2}{|c|}{ Explanatory variables } \\
\hline AGE & Age of the woman (in years). \\
\hline $\mathrm{EDC}$ & A continuous variable defined as the completed years of education. \\
\hline EXP & A continuous variable defined as: \\
\hline & Experience $=$ Age - Education -5 \\
\hline $\mathrm{EXP}^{2}$ & Square of Experience. \\
\hline PED & $\begin{array}{l}=1 \text { if the woman education level is up to Primary level } \\
=0 \text { otherwise }\end{array}$ \\
\hline SED & $\begin{array}{l}=1 \text { if the woman education level is up to Secondary level } \\
=0 \text { otherwise }\end{array}$ \\
\hline HED & $\begin{array}{l}=1 \text { if the woman education level is up to Higher level } \\
=0 \text { otherwise }\end{array}$ \\
\hline PCI & $\begin{array}{l}\text { A continuous variable defined as Per Capita income of the family in Pak. Rupees } \\
\text { which is attained by dividing total monthly family income by the total number of } \\
\text { family. }\end{array}$ \\
\hline PHA & $\begin{array}{l}=1 \text { if the women have assets in any form } \\
=0 \text { otherwise }\end{array}$ \\
\hline MAR & $\begin{array}{l}=1 \text { if the women are married } \\
=0 \text { otherwise }\end{array}$ \\
\hline HSL & $\begin{array}{l}=1 \text { if the woman's husband is salaried person } \\
=0 \text { otherwise }\end{array}$ \\
\hline FSP & $\begin{array}{l}=1 \text { if females belong to joint family system } \\
=0 \text { otherwise }\end{array}$ \\
\hline NDT & Total number of dependents in the family \\
\hline LCN & $\begin{array}{l}=1 \text { if the women are living in urban area } \\
=0 \text { otherwise }\end{array}$ \\
\hline $\mathrm{NCH}$ & Total number of children in the family \\
\hline
\end{tabular}

Table 3. Descriptive Statistics of some selected variables

\begin{tabular}{|lllll|}
\hline Variables & \multicolumn{1}{c}{ Mean } & \multicolumn{1}{c}{ Standard Deviation } & \multicolumn{1}{c}{ Skewness } & Kurtosis \\
\hline AGE & 38.11 & 13.25 & 0.11 & 2.23 \\
EXP & 110.50 & 13.50 & 0.16 & 2.25 \\
EXP2 & 687.2 & 667.24 & 1.14 & 3.62 \\
EDC & 10.62 & 3.82 & -0.50 & 3.02 \\
PED & 0.49 & 0.50 & 0.02 & 1.00 \\
SED & 0.17 & 0.38 & 1.75 & 4.06 \\
HED & 0.34 & 0.46 & 0.85 & 1.72 \\
PCI & 2387.70 & 2724.29 & 1.79 & 6.25 \\
PHA & 0.54 & 0.50 & -0.17 & 1.03 \\
MAR & 0.78 & 0.42 & -1.36 & 2.84 \\
HSL & 0.51 & 0.50 & -0.05 & 1.00 \\
FSP & 0.60 & 0.49 & -0.42 & 1.18 \\
NDP & 4.70 & 1.95 & 0.27 & 2.25 \\
LCN & 0.35 & 0.48 & 0.51 & 1.38 \\
NCH & 3.18 & 2.14 & -0.16 & 2.13 \\
\hline
\end{tabular}


Table 4. Correlation among explanatory variables

\begin{tabular}{|c|c|c|c|c|c|c|c|c|c|c|c|c|c|c|c|c|}
\hline & Variables & 1 & 2 & 3 & 4 & 5 & 6 & 7 & 8 & 9 & 10 & 11 & 12 & 13 & 14 & 15 \\
\hline 1 & AGE & 1.00 & & & & & & & & & & & & & & \\
\hline 2 & EXP & 0.96 & 1.00 & & & & & & & & & & & & & \\
\hline 3 & EXP2 & 0.91 & 0.95 & 1.00 & & & & & & & & & & & & \\
\hline 4 & EDC & 0.08 & -0.21 & -0.21 & 1.00 & & & & & & & & & & & \\
\hline 5 & PED & -0.06 & 0.07 & 0.12 & -0.46 & 1.00 & & & & & & & & & & \\
\hline 6 & SED & 0.03 & -0.13 & -0.16 & 0.58 & -0.65 & 1.00 & & & & & & & & & \\
\hline 7 & HED & 0.05 & 0.04 & 0.02 & 0.03 & -0.45 & -0.30 & 1.00 & & & & & & & & \\
\hline 8 & PCI & 0.17 & 0.19 & 0.18 & -0.08 & 0.05 & -0.11 & 0.03 & 1.00 & & & & & & & \\
\hline 9 & PHA & -0.11 & -0.09 & -0.08 & -0.05 & 0.10 & -0.22 & 0.12 & 0.37 & 1.00 & & & & & & \\
\hline 10 & MAR & 0.60 & 0.57 & 0.46 & 0.05 & -0.07 & 0.00 & 0.04 & 0.47 & 0.05 & 1.00 & & & & & \\
\hline 11 & HSL & 0.25 & 0.23 & 0.13 & 0.04 & -0.13 & -0.02 & 0.15 & 0.57 & 0.35 & 0.54 & 1.00 & & & & \\
\hline 12 & FSP & -0.32 & -0.33 & -0.29 & 0.04 & -0.05 & 0.02 & 0.07 & -0.52 & -0.14 & -0.43 & -0.34 & 1.00 & & & \\
\hline 13 & NDT & 0.36 & 0.33 & 0.28 & 0.10 & -0.07 & 0.03 & 0.07 & -0.34 & -0.20 & 0.35 & 0.04 & 0.25 & 1.00 & & \\
\hline 14 & LCN & -0.12 & -0.15 & -0.19 & 0.12 & -0.02 & 0.06 & 0.00 & -0.11 & -0.06 & -0.01 & 0.06 & -0.05 & 0.00 & 1.00 & \\
\hline 15 & $\mathrm{NCH}$ & 0.60 & 0.57 & 0.47 & 0.08 & -0.05 & 0.02 & 0.04 & 0.05 & -0.05 & 0.79 & 0.35 & -0.31 & 0.67 & 0.02 & 1.00 \\
\hline
\end{tabular}

Table 5. Logistic Regression Estimates

\begin{tabular}{|lllll|}
\hline \multicolumn{1}{r}{ Variables } & \multicolumn{1}{c}{ Coefficients } & \multicolumn{2}{c|}{ Z-statistic } & \multicolumn{2}{c|}{ Marginal Effects } \\
\hline C & $-3.55^{* * *}$ & -2.48 & -- & 0.00039 \\
AGE & $0.031^{*}$ & 1.78 & 0.012 & \\
EDC & $0.098^{* *}$ & 1.95 & -0.011 & \\
PCI & $-0.084^{*}$ & -1.84 & 0.083 & \\
PHA & $0.667^{* * *}$ & 2.86 & -0.029 & 164 \\
MAR & -0.234 & -1.05 & 0.137 & 0.267 \\
HSL & $1.10^{*}$ & 1.75 & 0.031 & \\
FSP & 0.249 & 1.30 & -0.046 & -0.127 \\
NDT & $-0.366^{*}$ & -1.69 & 0.055 & \\
LCN & $-1.013^{*}$ & -1.71 & Sample Size & \\
NCH & $0.443^{* *}$ & 1.93 & McFadden R ${ }^{2}$ & \\
\hline Log Likelihood & -52.57247 & & & \\
LR-Statistic (10 df) & 38.40478 & & & \\
Probability (LR) & 0.0003 & &
\end{tabular}

*** Significant at $1 \%$ level of significance $* *$ Significant at $5 \%$ level of significance * Significant at $10 \%$ level of significance

Table 6. Logistic Regression Estimates

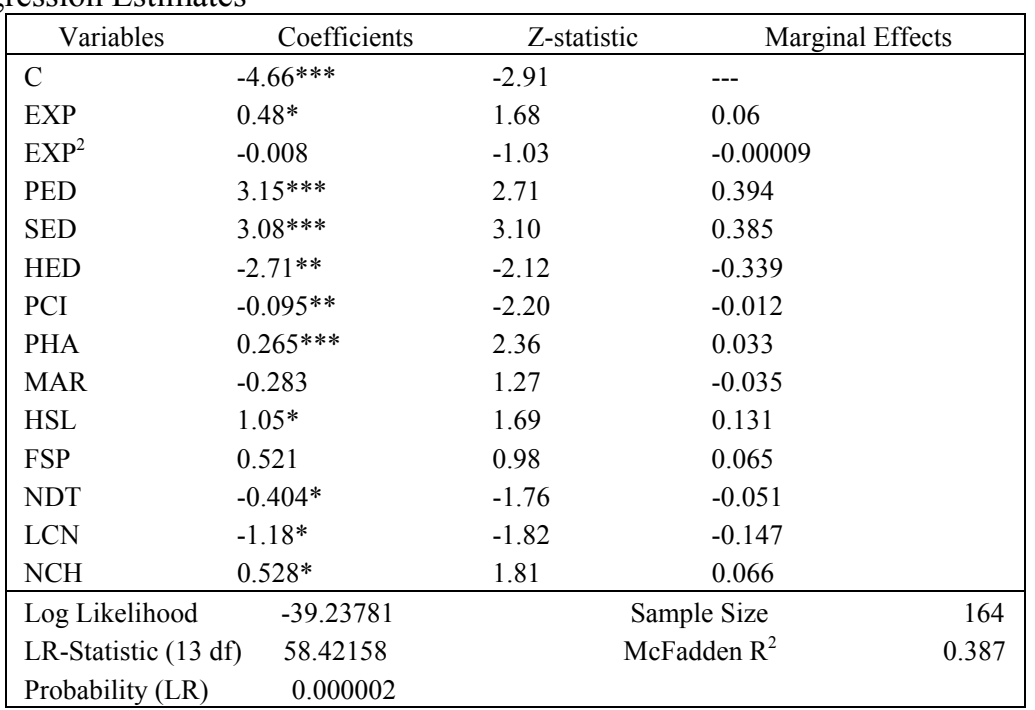

*** Significant at $1 \%$ level of significance ${ }^{* *}$ Significant at $5 \%$ level of significance $*$ Significant at $10 \%$ level of significance Non formal education is considered as base category 